\title{
Changes in Respiratory Pattern Resulting from the Use of a Facemask to Record Respiration in Newborn Infants
}

\author{
PETER J. FLEMING, ${ }^{(1)}$ M. R. LEVINE, AND A. GONCALVES \\ Department of Child Health, Bristol Maternity Hospital and Department of Physiology, University of Bristol, \\ Bristol, Great Britain
}

\begin{abstract}
Summary
Investigation of respiratory control requires an accurate measuring system which does not itself alter the pattern of respiration. We have used a transthoracic impedance pneumograph to investigate the effects of application of a face mask plus pneumotachograph or the face mask rim alone on tidal volume and respiratory frequency in 10 sleeping term infants aged 1-4 days. Application of the face mask rim led to a small but significant fall in respiratory frequency, $12 \%$ in quiet sleep (QS) and $17 \%$ in rapid eye movement (REM); with the application of the complete face mask plus pneumotachograph, changes were $10 \%$ and $14 \%$ in QS and REM, respectively. These changes were accompanied by rises in tidal volume of similar magnitude $(15 \%, 11 \%$ in QS and $21 \%, 17 \%$ in REM, respectively). These results suggest that the change in respiratory pattern is due mainly to trigeminal stimulation rather than respiratory loading; thus, recordings obtained by methods utilising face masks cannot be considered to represent undisturbed respiration, for at least the first 5 min of recording.
\end{abstract}

The study of respiratory control requires a measuring system that accurately records tidal volume and the respiratory waveform without itself altering the pattern of respiration. Commonly, ventilation is measured in terms of volume displacement or of air flow but there is some evidence that the use of a mouthpiece or face mask in adults or a face mask in preterm infants, which such measurement involves, disturbs the normal pattern of respiration $(2,3)$. We have examined this question in detail in normal, fullterm infants during sleep by measuring the effect of applying a face mask and pneumotachograph upon the respiratory pattern recorded by impedance pneumography.

\section{MATERIALS AND METHODS}

We measured respiration and sleep state in 10 normal, full-term infants during one sleep period at ages 1-4 days. Respiration was measured by means of the Bristol 4-lead, impedance pneumograph (7) with bilateral pairs of electrodes in the midaxillary line. Sleep state was estimated by means of bilateral electroencephalogram

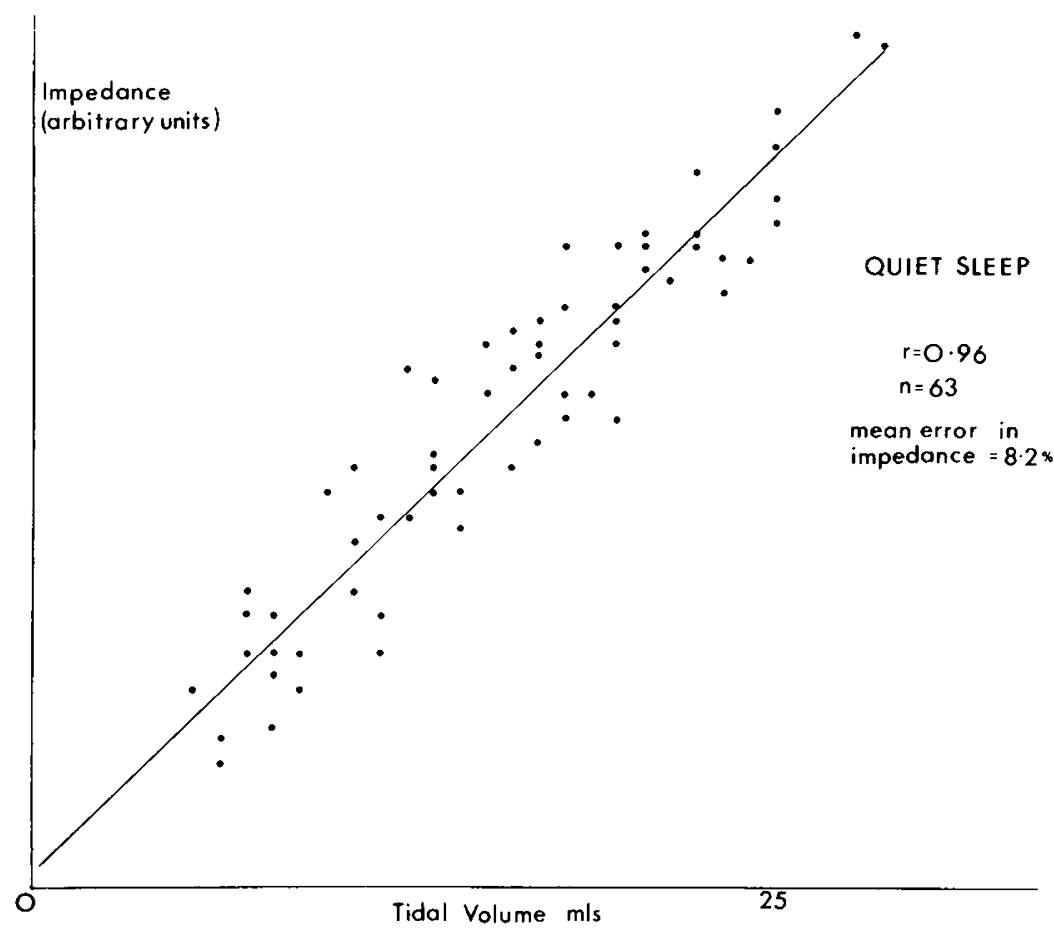

Fig. 1. The regression of tidal volume measured by impedance pneumography (arbitrary units) upon tidal volume measured by face mask system (ml). Sixty consecutive breaths (including two sighs and the widely varying breaths which follow) from one infant in quiet sleep. 
(EEG) and electroculogram (EOG) electrodes plus direct observation of eye movements (1). The pattern of respiration was not used as a criterion of sleep state. All studies were performed with the infants either supine or on their side, lightly clothed, in a perspex basinet at an ambient temperature of $24-25^{\circ} \mathrm{C}$.

The face mask system used was a Bennett size 3 ventilation mask fitted with a baffle to separate inflow from outflow, and supplied with a bias flow of warmed humidified air at 4 litres/ min. This system gives a negligible dead space (5). Flow was recorded by means of a heated Fleisch ' 0 ' pneumotachograph attached to the mask outflow port and connected to a Statham PM5-differential transducer. The signal was electronically integrated to give tidal volume and set to zero at the bias flow used. The pneumotachograph was calibrated by means of a constant volume reciprocating pump. The flow resistance of the mask alone was $0.009 \mathrm{mmH}_{2} \mathrm{O} \mathrm{ml} \mathrm{m}^{-1} \cdot \mathrm{sec}^{-1}$ and of the complete system with pneumotachograph was $0.048 \mathrm{mmH}_{2} \mathrm{O} \mathrm{ml} \mathrm{m}^{-1} \cdot \mathrm{sec}^{-1}$.

Each study consisted of a 3-min control period in a defined sleep state (QS or REM) followed by a 3-5 min period with the mask held in place over the infants face sufficiently firmly to prevent leaks. Care was taken to prevent airway obstruction by supporting the jaw and ensuring the mask was not pressed onto the top of the nose (4). This was followed by a further 3-min control period. In order to try and separate the effects of flow resistance through the pneumotachograph or partial airway obstruction from those of facial stimulation, similar recordings were made in eight of the infants using only the soft plastic rim from the mask held, as in other tests, firmly in place over the nasal bridge and cheeks, with the jaw supported. Studies in which a change of sleep state occurred or in which the infant moved or became restless for more than $20 \mathrm{sec}$ whilst the mask or rim was in place were rejected. In eight studies, the mask was held in place

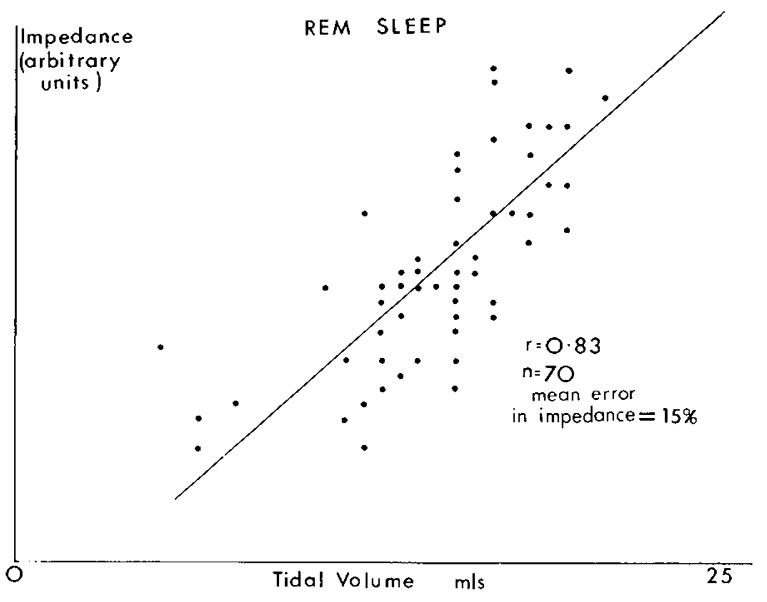

Fig. 2. The regression of tidal volume measured by impedance pneumography upon tidal volume measured by face mask system. Seventy consecutive breaths from one infant in REM sleep.

Table 1. The correlation between transthoracic impedance and pneumotachograph tidal volume estimates in 10 infants ${ }^{1}$

\begin{tabular}{lcc}
\hline State & Correlation coefficient & $\begin{array}{c}\text { Mean error }{ }^{2} \text { of } \\
\text { impedance signal }\end{array}$ \\
\hline QS & $0.95(0.80-0.98)$ & $8.8 \%(4-12 \%)$ \\
REM & $0.90(0.78-0.96)$ & $9.8 \%(7-15 \%)$ \\
\hline
\end{tabular}

${ }^{1}$ Values given are the median and range (in brackets).

${ }^{2}$ Root mean square deviation from best fit regression line; expressed as percentage of mean impedance signal.

\section{A. QUIET SLEEP}

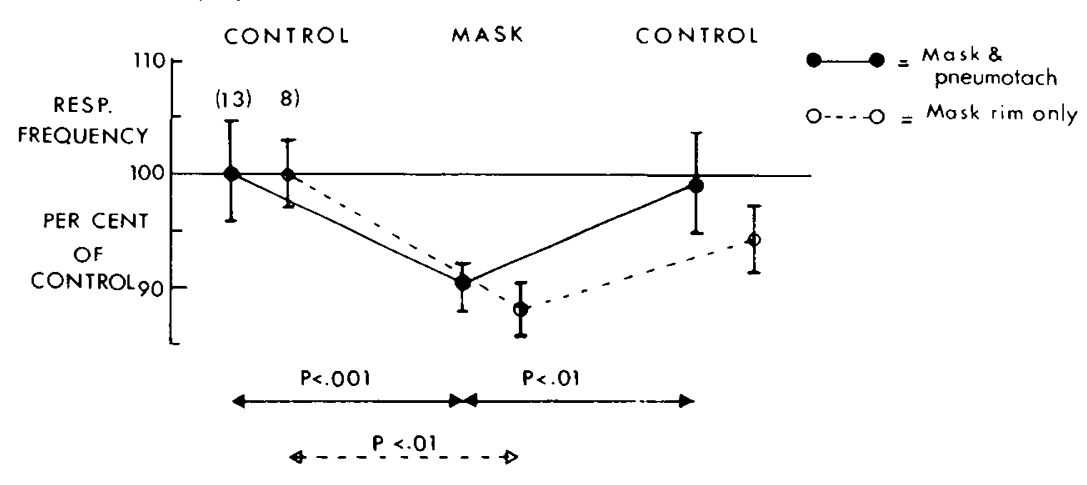

B. REM SLEEP

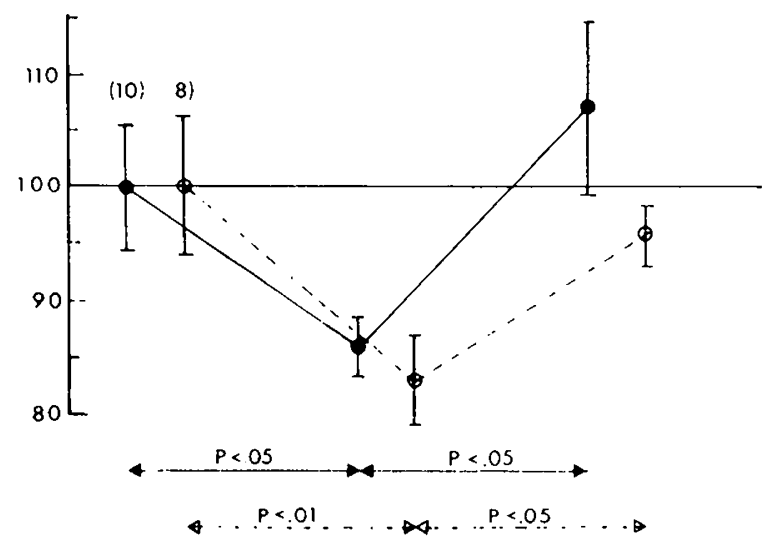

Fig. 3. A summary of the effect of applying the mask and pneumotachograph $(\Theta)$ or mask rim alone $(\bigcirc)$ upon respiratory frequency, expressed as a \% change from control, in: $A$, Quiet sleep and $B$, REM sleep. Numbers of studies are shown in brackets. Estimates of significance (Student's $t$ test) are * shown below each graph. Other differences are not significant. (The use of open and closed symbols are as for the graphs). 
by one operator (P. F.) and in two studies by another (A. G.). Results obtained by the two operators were not significantly different.

Any changes in respiratory frequency were calculated by averaging the number of breaths in 6-8 consecutive $30-\mathrm{sec}$ periods in the first control, experimental, and second control periods. Any deviation in the experimental period was then expressed as a $\%$ change from control values in each infant so that changes could be compared between infants. Changes in tidal volume (in arbitrary units) were averaged over the last min of the control period, over the first and fourth min of the experimental period and over the first min of the second control period. Average values for tidal volume and frequency have been expressed as mean \pm S.E. and the significance of any changes estimated by Student's $t$ test.

Signals were recorded by means of an eight channel polygraphic recorder (Devices U.K. Ltd.). The transthoracic impedance can be directly calibrated in ohms, but for the purposes of this study the impedance estimate of tidal volume was arbitrarily expressed in $\mathrm{mm}$ of pen deflection.

To test the linearity of the relationship between transthoracic impedance and pneumotachograph tidal volume signals, correlation coefficients, regression lines, and mean error (root mean square deviation from best fit regression line; expressed as \% of mean signal) in impedance signal were calculated for $1 \mathrm{~min}$ of recording in each state in each infant.

\section{RESULTS}

The regression of "tidal volume" (impedance) upon tidal volume (pneumotachograph) from one infant in QS and REM sleep is shown in Figures 1 and 2, respectively. The median values and ranges for correlation coefficients and mean errors are shown in Table 1. For the "worst case" values of mean error in impedance signals of $12 \%$ and $15 \%$ in QS and REM respectively, the S.E. of the mean for 40 breaths is $1.9 \%$ or $2.4 \%$, respectively. Thus, observed changes in mean impedance "tidal volumes" of $>3.8 \%$ or $>4.8 \%$ in QS and REM, respectively are statistically likely $(P$ $<0.05)$ to represent changes in true tidal volume.

The effects on respiratory frequency of applying the complete mask and pneumotachograph system or of the mask rim alone in QS and REM sleep are shown in Figure 3. Application of the mask and pneumotachograph (13 tests) or mask rim alone (8 tests) resulted respectively in an average $10 \%(P<0.001)$ and $12 \%(P$ $<0.01)$ reduction in respiratory frequency in QS. In REM sleep the effect of the mask and pneumotachograph (10 tests) and the mask rim alone (eight tests) was to produce respectively a $14 \%(P$ $<0.05)$ and $17 \%(P<0.01)$ fall in frequency.

Figure 4 shows the effects of the mask plus pneumotachograph or mask rim alone on impedance pneumograph estimates of tidal volume. Application of the mask plus pneumotachograph or mask rim alone led to increases in tidal volume in QS of $11 \%(P<0.05)$ and $15 \%(P<0.01)$, respectively. In REM application of the mask plus pneumotachograph led to a rise in tidal volume of $21 \%(P$ $<0.05)$ whilst the rim alone gave a rise of $17 \%(0.05<P<0.1)$. Changes in REM were less statistically significant because of the much greater variability of tidal volume in that state.

After removal of the mask or rim, tidal volume and frequency returned to values very close to control values (Figs. 3 and 4).

\section{DISCUSSION}

Our results show that the application of a face mask resulted in a fall in the frequency and rise in tidal volume in both QS and REM sleep. Similar results have been reported in awake adult man (2). Such changes could be caused by an increase in airway resistance due to partial airway obstruction (4) or to the flow resistance of the pneumotachograph. The latter explanation is unlikely, as flow resistance through the mask and pneumotachograph was very low-less than $10 \%$ of the expected total airway resistance (8)-and comparable to values published for other mask or pneumotachograph techniques $(9,10)$. Avoidance of partial airway obstruction by the mask is difficult even when great care

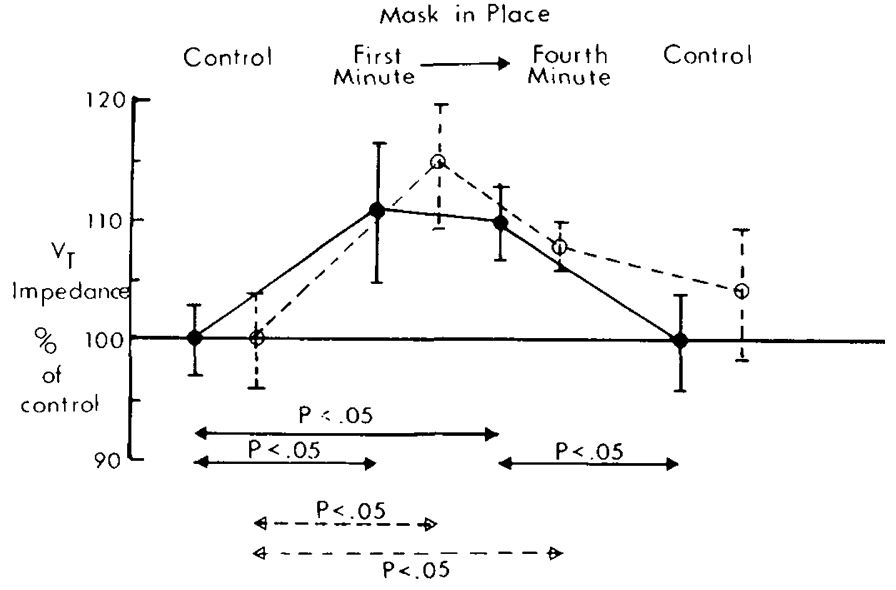

B.REM Sleep

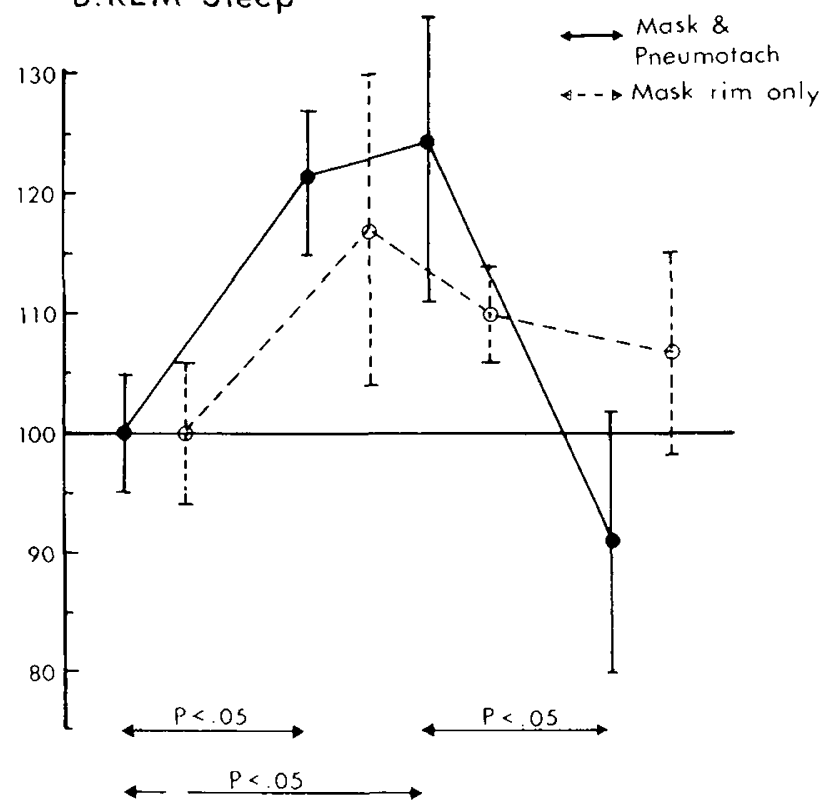

Fig. 4. A summary of the effect of applying mask rim (O) or mask plus pneumotachograph (-) upon tidal volume (impedance) expressed as \% change from control. The changes are recorded for the first and fourth min of the experimental period. Symbols for estimates of significance below each graph, as in Figure 3. $A$, Quiet sleep and $B$, REM sleep.

is taken to support the jaw, as on occasions the mask may impinge on the tip of the nose (4). Careful application of the rim alone diminished this latter possibility, but led to similar changes in tidal volume and frequency suggesting that nasal obstruction was not a significant factor.

The observed changes in respiratory pattern may therefore have been produced by stimulation of receptors in the trigeminal area. Such trigeminal stimulation gives rise to powerful cardiorespiratory reflexes in many newborn animals (6) and has been shown to produce hypoventilation in preterm infants (3).

Whatever the mechanism by which the observed changes were produced however, their importance lies in the observation that application of a face mask to an infant's face will change the normal respiratory pattern. Such changes, though small, occur in both QS and REM sleep, and persist for at least 5 min after application of the mask. Although minute ventilation is unlikely to be greatly affected, alveolar ventilation may well increase. In consequence any results based on the use of such techniques for recording respiration are likely to be correspondingly erroneous.

\section{REFERENCES AND NOTES}

1. Anders, T., Emde, R., and Parmelee, A: A manual of standardised terminology, techniques and criteria for scoring of states of sleep and wakefulness in 
newborn infants. U.C.L.A. Brain Information Service/B.R.I. Publications Office, Los Angeles, California (197i)

2. Askanazi, J., Silverberg, P. A., Foster, R. J., Hayman, A. I., Milic-Emili, J., and Kinney, J. M: Effects of respiratory apparatus on breathing pattern. J. Appl. Physiol. Respir. Environ. Exercise Physiol., 48: 577 (1980).

3. Chernick, V. and Avery, M. E: Response of premature infants with periodic breathing to ventilatory stimuli. J. Appl. Physiol., 2I: 434 (1966).

4. Doershuk, C. F., Downs, T. D., Matthews, L. W., and Lough, M.D: A method for ventilatory measurements in subjects 1 month-5 years of age: normal results and observations in disease. Pediatr. Res., 4: 165 (1970).

5. Goldman, S. L., Brady, J. P., and Dumpit, F. M: Increased work of breathing associated with nasal prongs. Pediatrics, 64: 160 (1979).

6. Haddad, G. G. and Mellins, R. B: The role of airway receptors in the control of respiration in infants. A review. J. Pediatr. 91: 281 (1977).

7. Olssen, T. and Victorin, L: Transthoracic impedance, with special reference to newborn infants and the ratio air-to-fluid in the lungs. Acta. Paediat. Scand., Supplement 207 (1970)

8. Stocks, J: Effect of nasogastric tubes on nasal resistance during infancy. Arch Dis. Child., 55: 17 (1980)

9. Stocks, J., Levy, N. M., and Godfrey, S: A new apparatus for the accurate measurement of airway resistance in infancy. J. Appl. Physiol. 43: 155 (1977).

10. Thach, B. T. and Taeusch, H. W: Sighing in newborn human infants. Role of inflation-augmenting reflex. J. Appl. Physiol., 41: 502 (1976).

11. Requests for reprints should be addressed to: Dr. P. J. Fleming, Department of Child Health, Bristol Maternity Hospital, Southwell Street, Bristol, BS2 8EG, Great Britain.

12. This research was supported by PHS grant HDO 9456 and a grant from Action Research.

13. Received for publication January 14, 1982

14. Accepted for publication April 23, 1982. 